\title{
Uterine leiomyosarcomas and leiomyomas: Two similar uterine solid tumors, totally different for prognosis.
}

\author{
Andrea Tinelli \\ Department of Obstetrics and Gynecology, Division of Experimental Endoscopic Surgery, Imaging, Technology and Minimally \\ Invasive Therapy, Vito Fazzi Hospital,Piazza Muratore, 73100 Lecce, Italy.Tel/Fax: +39/0832/661511. E-mail: \\ andreatinelli@gmail.com \\ Received: $2011-08-30$ \\ DOI : $10.5430 /$ jst.v1n2p29 \\ Accepted: $2011-09-30$ \\ Published: $2011-10-20$ \\ URL: http://dx.doi.org/10.5430/jst.v1n2p29 \\ The uterine leiomyosarcoma (LMS) is a rare sarcoma arising from the smooth muscle cells found within the \\ myometrium, it is clinically aggressive smooth muscle malignancy, accounting for $2 \%$ to $6 \%$ of uterine malignancies \\ and an annual incidence of 1.7 per 100,000 women. Although uterine malignancies such as endometrial cancer are \\ common, uterine LMS accounts for only $1 \%$ of uterine cancers and is a part of uterine sarcomas' group, who comprises: \\ carcinosarcoma (formerly known as MMMT, malignant mixed Mullerian tumor) (40\% to 50\%), leiomyosarcoma (30\% \\ to $40 \%$ ) and endometrial stromal sarcoma (10\% to $15 \%)$. Every group has its own risk factors, presenting symptoms, \\ treatment response and prognosis. ${ }^{1}$
}

Uterine smooth muscle tumors arise from the uterine myometrium and include leiomyomas (or fibroids) and uterine LMS, who exhibits histological features similar to that observed in soft tissue leiomyosarcomas. In fact, smooth muscle cell tumours may be divided into three groups: benign (leiomyoma), malignant (leiomyosarcoma), and tumors of unknown malignant potential. ${ }^{2}$

The behavior and treatment of leiomyomas and uterine LMS, however, markedly differs with a totally different prognosis. Often referred to as fibroids, uterine leiomyomas are benign smooth muscle tumors, are quite common, with high prevalence rates among women and symptoms and signs as, pain, pressure symptoms, menstrual disorders and infertility or reproductive dysfunction. By contrast, uterine LMS are clinically aggressive smooth muscle malignancies with poor prognosis “quad vitam”. Most cases arise de novo and not from pre-existing leiomyomas. ${ }^{3,4}$

As leiomyomas enlarge, they may outgrow their blood supply, resulting in various types of degeneration: hyaline or myxoid degeneration, calcification, cystic degeneration, and red degeneration. ${ }^{3}$

A rapid increase in size of a uterine tumor in a post menopausal woman should always prompt an investigation to exclude the possibility, of LMS arising. The differential diagnosis of leiomyomas includes adenomyosis, solid adnexal mass, focal myometrial contraction, and LMS. Fibroids tumors are usually solitary with a large, poorly circumscribed mass and a soft fleshy consistency with necrosis. ${ }^{5}$

There is overlap in the age of diagnosis for fibroids and uterine LMS. However, patients with uterine LMS tend to be older. Uterine fibroids tend to be diagnosed during the fourth or fifth decade of life, while uterine LMS is usually discovered during the fifth or sixth decades of life. ${ }^{6}$

The incidence of uterine LMS associated with surgical cases for presumed leiomyomas is low, at approximately $0.5 \%{ }^{7}$ 
This risk increases with age and is as high as $1.7 \%$ for patients over the age of 60 years. ${ }^{7}$ Although a rapidly growing uterus has often been considered to be at high risk for uterine LMS, a review of the literature does not support this belief. The incidence of sarcoma in patients having surgery for 'rapidly growing' leiomyomas is only $0.27 \%{ }^{8}$

As reported in literature, uterine leiomyomas are benign tumors composed predominantly of smooth muscle cells separated by variable amounts of fibrous connective tissue with a good prognosis. ${ }^{3,6,9}$

Uterine LMS appear as soft, fleshy and grayish yellow with areas of necrosis and hemorrhage. Histologically, the diagnosis of uterine LMS relies on the presence of three criteria. Unambiguous uterine LMS demonstrates a Mitotic Index (mitotic figures per ten high-powered field $[\mathrm{HPF}]=$ ten, cytological atypia and the presence of coagulative necrosis). Most pathologists will diagnose uterine LMS in cases where two of the three criteria are present. By contrast, uterine leiomyomas present as well-circumscribed, firm masses with whorled white-tan surfaces. On microscopic evaluation, fibroids demonstrate interlacing, spindle-shaped smooth muscle cells. The nuclei are described as cigar shaped. There is no evidence of necrosis or cytological atypia. Although mitotic figures may be present, they are rare. The Mitotic Index is typically less than $1 .{ }^{10,11}$

Although there is no true capsule, these tumors are well circumscribed and surrounded by a pseudocapsule, not present in LMS analysis. ${ }^{12}$

The uterine fibroid pseudocapsule is a fibro-neurovascular structure surrounding leiomyoma, separating it from normal peripheral myometrium. The fibroid pseudocapsule is composed by fibrotic tissue, vessels and a neurovascular network rich of neurofibers, as the neurovascular bundle surrounding prostate, but of this intriguing structure I'll discuss later in more detail. ${ }^{13}$

Returning to discuss the difference among fibroids and LMS, the leiomyomas cut surface has a characteristic whorl-like, trabeculated appearance, their size of uterine leiomyomas is variable, ranging from microscopic to large tumors that fill the abdomen and leiomyomas may be single or, more frequently, multiple. ${ }^{3,6,10,11}$

Although little is known about the factors responsible for the initial neoplastic myometrial transformation, it is hypothesized that each leiomyoma arises from a single cell in the myometrium. ${ }^{1,14}$

Several observations suggest that estrogens and progesterone play an important role in the growth of uterine fibroids: they occur in women of reproductive age, often enlarge during pregnancy or during oral contraceptive use, and regress after menopause. . $^{3,13,15}$

As fibroids enlarge, they may outgrow their blood supply, recently evaluated as possible marker of leiomyoma transformations. In fact, the myoma pseudocapsule vessels were studied by a preliminary three-dimensional mathematical model, who showed an increase vascular tortuosity, disarray, an abnormal branching and the presence of "cul-de-sac" pseudocapsule vessels. All of these features are similar to malignant neoplastic tissue vessels features, present in malignant tumors. It was not possible in this study to clarify if the pseudocapsule vasculature network could be sustained by mechanical and inflammatory effects of myoma on myometrium, or produced by a sort of neoplastic type of neoangiogenesis due to the fibroid growth or transformation, or even by a muscle and tissue healing process, such as a neurovascular preparative reaction of female body to a fibroid expulsion (pedunculated fibroids), necrosis or degeneration (hyaline or myxoid degeneration, calcification, cystic degeneration, and red or hemorrhagic degeneration), allowing a normal uterine restoration. ${ }^{16}$

Thus, there is little known about healing of the uterine scar tissue after surgical injury, as myomectomy and cesarean sections. However wound healing is a dynamic, interactive process involving neuromediators, angiogenetic factors, neuropeptides, blood cells, extracellular matrix, and parenchymal cells that follows three complex and overlapping phases: inflammation, tissue formation, and tissue remodeling. ${ }^{17}$

For this reason it is not clear what the origin and the goal of abnormal vascularization of fibroid pseudocapsule around the fibroids, and it is not possible to indicate the pseudocapsule vessel abnormality as marker of neoplastic transformation.

The categorization as either benign uterine leiomyoma or malignant uterine LMS is relatively straightforward for the majority of uterine smooth muscle tumors. However, a limited but significant number of uterine smooth muscle tumors 
elude easy classification. Uterine neoplasms, which fail to meet criteria for uterine leiomyoma or for uterine LMS, are often referred to as leiomyoma variants: these tumors demonstrate discordance with one or more features of uterine LMS. The category includes atypical, cellular, mitotically active and bizarre leiomyoma. Other terms include hydropic leiomyomas, myxoid leiomyomas, epithelioid leiomyomas, highly cellular leiomyomas and leiomyomas with unusual growth patterns.

Kempson and Hendrickson acknowledge that a small group of uterine smooth muscle tumors exist for which we have insufficient understanding to predict clinical outcome. ${ }^{18}$

The authors apply the term smooth muscle tumors of low malignant potential (STUMP) to these neoplasms. ${ }^{19}$

They include the following: smooth muscle tumors with minimal atypia with a low Mitotic Index but with uncertainty as to the histological type (i.e., standard, myxoid or epithelioid); smooth muscle tumors with standard differentiation, marked diffuse severe atypia, low Mitotic Index and uncertainty concerning the presence of coagulative tumor cell necrosis; smooth muscle tumors with moderate-to-severe atypia with an uncertain Mitotic Index secondary to the possibility that possible mitotic figures may be degenerating nuclei mimicking mitotic figures.

Rapid growth of a leiomyoma is not a reliable indication of sarcomatous degeneration. ${ }^{20}$

In a retrospective review of 580 leiomyosarcomas, less than $3 \%$ of patients had a rapidly enlarging uterus. In the same review, only one leiomyosarcoma was found in 371 women operated on for rapidly growing leiomyomas. ${ }^{20}$

Even the symptoms can help in differential diagnosis: once again, patients with uterine LMSs report symptoms similar to those associated with leiomyomas. These include vaginal bleeding, pelvic mass and pain. About the differential preoperative diagnosis of fibroids and LMSs, Magnetic resonance (MR) imaging is the most accurate imaging technique for detection and localization of leiomyomas. On T2-weighted images, non-degenerated leiomyomas appear as wellcircumscribed masses of decreased signal intensity; however, cellular leiomyomas can have relatively higher signal intensity on T2-weighted images and demonstrate enhancement on contrast material-enhanced images. Degenerated leiomyomas have variable appearances on T2-weighted images and contrast-enhanced images. ${ }^{21}$

Although it has been suggested that an irregular margin of a uterine leiomyoma at MR imaging is suggestive of sarcomatous transformation, ${ }^{21,22}$ the specificity of this finding has not been established. The ability of MR imaging to allow differentiation of cellular or degenerated leiomyoma from leiomyosarcoma of the uterus has not been assessed, to our knowledge. The diagnosis of leiomyosarcoma is often first established by a pathologist after surgical removal of a presumed benign uterine mass. 9,23

One more time, a diagnosis of leiomyosarcoma is safely established only by histology.

Although rare, as mentioned previously, uterine LMS is an aggressive disease with poor prognosis, and account for a greatly disproportionate amount of deaths from uterine cancers. The optimal treatment of uterine leiomyosarcomas is surgery, but data from the Mayo Clinic demonstrates median recurrence-free survival of 2.2 years and median diseasespecific survival of 4.9 years. ${ }^{24}$

Several factors have consistently been demonstrated to be accurate prognostic indicators. Most notably, increased tumor grade, higher stage and elevated mitotic count per ten HPF have been shown to be predictive of adverse outcome. ${ }^{25}$

A recent review demonstrated 5-year disease-specific survival rates stage I, II, III and IV uterine LMS of 75.8\%, 60.1\%, $44.9 \%$ and $28.7 \%$, respectively. ${ }^{25}$

Other factors, including smaller tumor size, younger age and premenopausal status, have been correlated in some investigations with improved survival. Recently, the absence of vascular space involvement was noted to be correlated with enhanced survival. ${ }^{26}$

A risk-assessment index based on a retrospective review of 208 uterine LMS patients was highly predictive of diseasespecific survival. The distribution of points was as follows: one point for age 51 years or older, tumor size larger than $5 \mathrm{~cm}$ or stage II-IV disease; two points for grade 2 to 4 . Patients were then classified as low risk (0 to 1 points), 
intermediate risk (2 to 3 points) or high risk (4 to 5 points). There were no disease-specific deaths in the low-risk group. This index may help to counsel patients appropriately. ${ }^{27}$

Discussing on leiomyomas' treatment, in recent years, new advancements in endoscopic surgery, including the use of laparoscopic or robotic surgery in leiomyomas removal, have been considered as the true alternative to laparotomy with numerous advantages, such as short hospitalization, decreased need for postoperative analgesia, less intraoperative blood loss, and good outcomes in subsequent pregnancy. ${ }^{6}$ Last evidences on the neurofibers and neuropeptides in fibroid pseudocapsule suggest a new horizon in endoscopic gynecological surgery, which can be called: intracapsular fibroid nerve-sparing laparoscopic "microsurgery", or intracapsular fibroid nerve-sparing robotic assisted "nanosurgery", in case of robotic magnification. ${ }^{13}$ A great advantage of intracapsular laparoscopic myomectomy is the reproducibility of its application for all laparoscopic myomectomies, as a safe, feasible and minimally invasive technique. ${ }^{12}$ Intracapsular myomectomy enhances myometrium integrity peripheral to fibroid site, by preserving the neurovascular bundle and neurotransmitters surrounding fibroids, for uterine healing and the myometrium restoration after surgery. Moreover, allowing corrected myometrial healing, intracapsular myomectomy should preserve reproductive outcomes and normal labor and delivery, for less bleeding, better neurovascular bundle sparing for scar quality, and post-operative adhesions reduction. ${ }^{6,13}$

Concluding, differently from uterine leiomyoma, LMS is a rare but extremely aggressive subtype of uterine malignancy from mesenchymal elements, that account for $3 \%$ of uterine cancers, consists of several histological types, and the strongest prognostic factor for all the sarcomas is the stage at diagnosis. Recently, a new International Federation of Gynecology and Obstetrics (FIGO) classification and staging system was specifically designed for uterine sarcomas in an attempt to reflect their differing biological behavior. ${ }^{29}$

Exclusion of several histologic variants of leiomyoma, as well as "smooth muscle tumors of uncertain malignant potential," frequently misdiagnosed as LMS, has made apparent that LMSs are associated with poor prognosis even when seemingly confined to the uterus. ${ }^{2,9}$

Radiological diagnosis prior to surgery is difficult, with the diagnosis frequently made post-operatively. In fact, because of tumor rarity and histopathologic diversity, a way to effectively diagnose an LMS before surgery has not yet been identified, with subsequent bad histological surprises after a fibroid or uterine removal. ${ }^{30}$

Finally, no standardized treatment for any histological type has yet been established and overall survival is poor: 5-year survival rates of $50 \%$ to $70 \%$ for patients in stage I and 0 to $20 \%$ for the remaining stages. Surgery remains the mainstay of treatment for uterine sarcoma, demonstrating a curative potential regardless of histological type. ${ }^{31}$

Effective adjuvant therapy to prolong survival has not yet been established. Because neither currently available radiation therapy nor different combinations of cytotoxic chemotherapeutic agents is likely to have a major impact on the course of uterine sarcoma, alternative approaches such as molecularly targeted therapies need to be explored.

\section{REFERENCES}

[1] D'Angelo E, Prat J. Uterine sarcomas: a review. Gynecol Oncol. 2010;116(1):131-139. PMid:19853898 http://dx.doi.org/10.1016/j.ygyno.2009.09.023

[2] Rosai J. Ackerman's Surgical Pathology. Ninth Edition. Mosby, 2004.

[3] Lethaby A, Vollenhoven B. Fibroids (uterine myomatosis, leiomyomas). Clin Evid (Online). 2011 Jan 11;2011. pii: 0814.

[4] Amant F, Coosemans A, Debiec-Rychter M, Timmerman D, Vergote I. Clinical management of uterine sarcomas. Lancet Oncol. 2009;10(12):1188-1198. http://dx.doi.org/10.1016/S1470-2045(09)70226-8

[5] Wu TI, Yen TC, Lai CH. Clinical presentation and diagnosis of uterine sarcoma, including imaging. Best Pract Res Clin Obstet Gynaecol. 2011 Aug 3. [Epub ahead of print]

[6] Tinelli A, Malvasi A, Hudelist G, Cavallotti C, Tsin DA, Schollmeyer T, Bojahr B, Mettler L. Laparoscopic intracapsular myomectomy: comparison of single versus multiple fibroids removal. An institutional experience. J. Laparoendosc. Adv. Surg. Tech. A. 2010;20(8):705-711. http://dx.doi.org/10.1089/lap.2010.0082

[7] Leibsohn S, d'Ablaing G, Mishell DR Jr. Schlaerth JB. Leiomyosarcoma in a series of hysterectomies performed for presumed uterine leiomyomas. Am. J. Obstet. Gynecol.1990;162,968-974.PMid:2327466 
[8] Parker WH, Fu YS, Berek JS. Uterine sarcoma in patients operated on for presumed leiomyoma and rapidly growing leiomyoma. Obstet. Gynecol. 1994;83,414-418.PMid:8127535

[9] Prayson RA, Hart WR. Pathologic considerations of uterine smooth muscle tumors. Obstet Gynecol Clin North Am1995; 22:637657.PMid:8786875

[10] Bell SW, Kempson RL, Hendrickson MR. Problematic uterine smooth muscle neoplasms. A clinicopathologic study of 213 cases. Am. J. Surg. Pathol.1994;18:535-558. PMid:8179071 http://dx.doi.org/10.1097/00000478-199406000-00001

[11] Hendrickson MR, Kempson RL. Pure mesenchymal tumours of the uterine corpus. In: Haines and Taylor, Textbook of Obstetrical and Gynecolgical Pathology. Churchill Livingstone, Edinburgh, UK, 1995: 519.

[12] Tinelli A, Malvasi A, Rahimi S, Negro R, Cavallotti C, Vergara D, Vittori G, Mettler L. Myoma pseudocapsule: a new-old endocrinoanatomical entity to exploit in uterine myomectomy. Gynecol. Endocrinol. 2009; 25(10):661-667. PMid:19526398 http://dx.doi.org/10.1080/09513590903015502

[13] Mettler L, Tinelli A, Hurst BS, Teigland CM, Sammur W, Dell'Edera D, Negro R, Gustapane S, Malvasi A. Neurovascular bundle in fibroid pseudocapsule and its neuroendocrinologic implications. Expert Rev Endocrinol Metab 2011; 6(5) [in press]. PMid:15681023 http://dx.doi.org/10.1586/eem.11.62

[14] Seddon BM, Davda R. Uterine sarcomas--recent progress and future challenges. Eur J Radiol. 2011;78(1):30-40.PMid:21247711 http://dx.doi.org/10.1016/j.ejrad.2010.12.057

[15] Rein MS, Barbieri RL, Friedman AJ. Progesterone: a critical role in the pathogenesis of uterine myomas. Am J Obstet Gynecol 1995; 172:14-18. http://dx.doi.org/10.1016/0002-9378(95)90077-2

[16] Malvasi A, Tinelli A, Rahimi S, D'Agnese G, Rotoni C, Dell'edera D, Tsin DA, Cavallotti C. A three-dimensional morphological reconstruction of uterine leiomyoma pseudocapsule vasculature by the Allen-Cahn mathematical model. Biomed Pharmacother. 2011;65(5):359-63. http://dx.doi.org/10.1016/j.biopha.2011.04.018

[17] Berczi I, Quintanar-Stephano A, Kovacs K. Neuroimmune regulation in immunocompetence, acute illness, and healing. Ann N Y Acad Sci. 2009;1153:220-39. PMid:19236345 http://dx.doi.org/10.1111/j.1749-6632.2008.03975.x

[18] Kempson RL, Hendrickson MR. Smooth muscle, endometrial stromal, and mixed Mullerian tumors of the uterus. Mod. Pathol. 2000;13:328342. PMid:10757342 http://dx.doi.org/10.1038/modpathol.3880055

[19] Ng JS, Han A, Chew SH, Low J. A clinicopathologic study of uterine smooth muscle tumors of uncertain malignant potential (STUMP). Ann Acad Med Singapore. 2010;39(8):625-8.PMid:20838704

[20] Parker WH, Fu YS, Berek JS. Uterine sarcoma in patients operated on for presumed leiomyoma and rapidly growing leiomyoma. Obstet Gynecol 1994; 83:414-418.PMid:8127535

[21] Tanaka YO, Nishida M, Tsunoda H, Okamoto Y, Yoshikawa H. Smooth muscle tumors of uncertain malignant potential and leiomyosarcomas of the uterus: MR findings. J Magn Reson Imaging. 2004;20(6):998-1007. PMid:15558559 http://dx.doi.org/10.1002/jmri.20207

[22] Pattani SJ, Kier R, Deal R, Luchansky E. MRI of uterine leiomyosarcoma. Magn Reson Imaging 1995; 13:331-333. http://dx.doi.org/10.1016/0730-725X(95)93813-5

[23] Leibsohn S, d'Ablaing G, Mishell DR, Jr, Schlaerth JB. Leiomyosarcoma in a series of hysterectomies performed for presumed uterine leiomyomas. Am J Obstet Gynecol 1990;162:968-976.PMid:2327466

[24] Giuntoli RL 2nd, Metzinger DS, DiMarco CS et al. Retrospective review of 208 patients with leiomyosarcoma of the uterus, prognostic indicators, surgical management, and adjuvant therapy. Gynecol. Oncol. 2003;89:460-469. http://dx.doi.org/10.1016/S0090-8258(03)00137-9

[25] Nagase S, Katabuchi H, Hiura M, et al; Japan Society of Gynecologic Oncology. Evidence-based guidelines for treatment of uterine body neoplasm in Japan: Japan Society of Gynecologic Oncology (JSGO) 2009 edition. Int J Clin Oncol. 2010;15(6):531-42. PMid:21069552 http://dx.doi.org/10.1007/s10147-010-0138-6

[26] O'Cearbhaill R, Hensley ML. Optimal management of uterine leiomyosarcoma. Expert Rev Anticancer Ther. 2010;10(2):153-69. PMid:20131992 http://dx.doi.org/10.1586/era.09.187

[27] Amant F, Coosemans A, Debiec-Rychter M, Timmerman D, Vergote I. Clinical management of uterine sarcomas. Lancet Oncol. 2009;10(12):1188-98. http://dx.doi.org/10.1016/S1470-2045(09)70226-8

[28] Nam JH, Park JY. Update on treatment of uterine sarcoma. Curr Opin Obstet Gynecol. 2010;22(1):36-42. PMid:19923988 http://dx.doi.org/10.1097/GCO.0b013e328334d90f

[29] FIGO staging for uterine sarcomas. Int J Gynaecol Obstet 2009; 104: 179. PMid:20695826 http://dx.doi.org/10.1016/j.ijgo.2008.12.009

[30] Sohaib SA, Verma H, Attygalle AD, Ind TE. Imaging of uterine malignancies. Semin Ultrasound CT MR. 2010;31(5):377-87. PMid:20974357 http://dx.doi.org/10.1053/j.sult.2010.07.005

[31] Nam JH. Surgical treatment of uterine sarcoma. Best Pract Res Clin Obstet Gynaecol. 2011 Jul 15. [Epub ahead of print] 